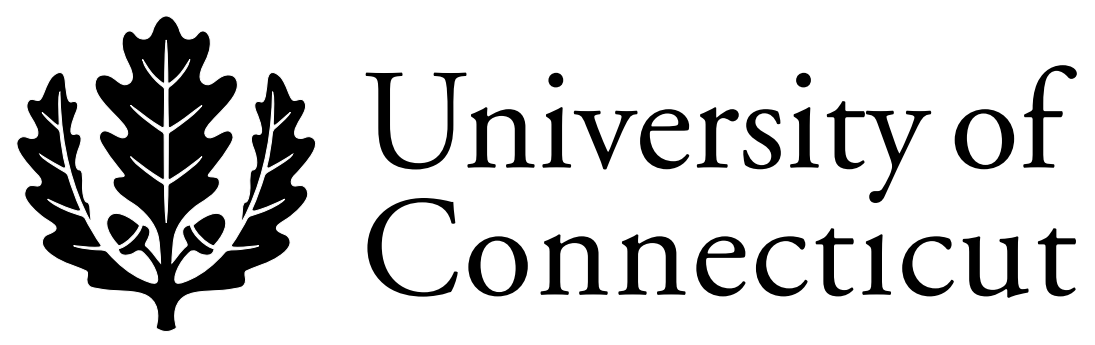

Department of Economics Working Paper Series

\title{
A Simple Theory of Increasing Penalties for Repeat Offenders
}

Thomas J. Miceli

University of Connecticut

Catherine Bucci

Working Paper 2004-39

November 2004

341 Mansfield Road, Unit 1063

Storrs, CT 06269-1063

Phone: (860) 486-3022

Fax: (860) 486-4463

http://www.econ.uconn.edu/ 


\begin{abstract}
A feature of many penal codes is that punishments are more severe for repeat offenders, yet economic models have had a hard time providing a theoretical justification for this practice. This paper offers an explanation based on the wage penalty suffered by individuals convicted of crime. While this penalty probably deters some first-timers from committing crimes, it actually hampers deterrence of repeat offenders because of their diminished employments opportunities. We show that in this setting, an escalating penalty scheme is optimal and time consistent.
\end{abstract}

Journal of Economic Literature Classification: K14, K42

Keywords: Criminal enforcement, repeat offenders 


\section{A Simple Theory of Increasing Penalties for Repeat Offenders}

\section{Introduction}

One of the most pervasive features of actual criminal punishment schemes is the increasing severity of punishments for repeat offenders. This is reflected both in federal sentencing guidelines (Champion, 1989), and in recent "three strikes" legislation enacted by many states (Shepherd, 2002). Yet economic models of crime have had surprising difficulty in explaining this practice. The reason may be due to the traditional focus of such models on setting criminal punishments so that only "efficient crimes" are committed. If, by committing a criminal act, the offender signals that he values the act more than the cost that it imposes on society, then why should he face a higher sanction if he chooses to commit the same, efficient act again? It follows that increasing penalties can only be justified if uniform penalties somehow result in underdeterrence. ${ }^{1}$

Several previous studies have examined this and other rationales for increasing penalties, but, as noted, they have been hard pressed to justify them. For example, Polinsky and Rubinfeld (1991) show that increasing penalties may be an optimal way to sort offenders who differ in their illicit gains from committing crimes, but this result only holds under certain parameter values. Flat and decreasing penalty schedules are also possible. Polinsky and Shavell (1998) derive a penalty scheme in which repeat offenders may face harsher punishments compared to first-timers, but this is only true in the following qualified sense. First-timers face less severe punishments than repeaters in the

\footnotetext{
${ }^{1}$ Polinsky and Shavell (2000, p. 67) and Posner (2003, p. 228) make this point.
} 
second of two periods, but repeaters face the same (maximal) sanction for their crimes in each period. Thus, the penalty on a particular offender never escalates. Chu, $\mathrm{Hu}$, and Huang (2000) show that increasing punishments for repeat offenders are justified if defendants are sometimes erroneously convicted, based on the presumption that the probability of error declines with each subsequent arrest. Other studies, however, show that, for various reasons, optimal deterrence may actually involve declining penalties for repeat offenders (Burnovsky and Safra, 1994; Dana, 2001; and Emons, 2003). Overall, one gets the impression that economic models have overlooked an important aspect of the repeat offender problem.

This paper offers a different explanation for rising penalties based on a factor that apparently has not been considered in this context—namely, the wage discount associated with criminal conviction. While the existence of such a discount has been welldocumented in the literature for a broad range of crimes and offender types, ${ }^{2}$ the conventional wisdom has been that the prospect of lost future income should actually enhance deterrence (Nagin and Waldfogel, 1998). We show that this logic is correct with respect to first-time offenders who are contemplating their first criminal act (the so-called "full deterrence" effect (Shepherd, 2002)), but once an offender has a record, the wage discount reduces deterrence by making legal employment less attractive compared to crime. Thus, to maintain a given level of deterrence for offenders with a record, the criminal sanction has to be raised. The model in this paper shows that such an escalating penalty scheme emerges as the optimal, time-consistent policy in a simple setting where punishment is costly to impose, and all crimes should be deterred. ${ }^{3}$

\footnotetext{
${ }^{2}$ See, for example, Lott (1992a, b), Grogger (1995), and Nagin and Waldfogel (1995, 1998).

${ }^{3}$ However, we expect the result to hold for more general formulations.
} 


\section{The Model}

Consider a population of risk neutral potential offenders who can commit criminal acts in two periods. Offenders receive a private return of $b$ dollars from each act committed and face an expected penalty that depends on the probability of apprehension, $p$, and a sanction that potentially depends on their criminal record. Specifically, first-time offenders in either period are subject to a sanction $s_{1}$ (measured in dollars) if caught, while repeat offenders (those with a past conviction) are subject to a sanction $s_{2}$. (Note that offenders who committed an act in period one but were not caught are treated as first-timers if caught for a second act in period two.) We make the following additional assumptions:

A1: The probability of apprehension, $p$, is fixed for both periods and independent of the offender's criminal record. This assumption simplifies the analysis without affecting the basic conclusions. ${ }^{4}$

A2: We assume that all crimes should definitely be deterred. This assumption is also made primarily for simplicity.

A3: We consider only non-monetary sanctions - that is, sanctions that are costly to impose. This assumption, along with the next one, ensures that enforcers will set the sanction as low as possible, given $p$, to achieve the desired level of deterrence.

A4: We assume that a constant fraction, $\alpha$, of individuals in each period are undeterrable, reflecting irrationality, miscalculation, or a lapse in judgment. ${ }^{5}$ Further, to

\footnotetext{
${ }^{4}$ Our results would be affected if $p$ could differ depending on the offender's record, for example, if police devoted more effort to apprehending repeat offenders. In that case, increased deterrence of repeat offenders (if that were desirable) could be achieved by increasing $p$ rather than increasing $s_{2}$. It seems unlikely, however, that the police could know ahead of time which crimes were committed by repeat offenders. The fact that $p$ is not a choice variable does not matter given that we are focusing on non-monetary penalties (see assumption A3) since it will not be optimal to employ the strategy of making the sanction maximal while setting $p$ as low as possible. (See Emons $(2003,2004)$ for models in which $p$ is endogenous.)
} 
keeps things simple, we assume that the probability that an individual offender will be undeterrable is the same for all offenders in each period (regardless of their past behavior) and equal across the two periods. ${ }^{6}$ (That is, lapses can be temporary.) Analytically, this assumption guarantees that some punishment costs will be incurred in each period, thus foreclosing the (unrealistic) enforcement strategy of setting $s_{1}$ and $s_{2}$ so high that all potential offenders are deterred.

A5: We assume that individuals who choose not to commit an offense in a given period can earn $y$ dollars in legal employment if they have no criminal record, but they can only earn $y-\varepsilon$ dollars if they have a record, where $\varepsilon$ is the earnings penalty associated with criminal conviction. Of course, this penalty is only relevant in period two and only then if the individual committed an act in period one and was caught. ${ }^{7}$ Finally, we assume that $b>y$, implying that rational offenders will prefer crime over legal employment in the absence of criminal punishment.

We derive the optimal structure of penalties by first identifying the constraints on $s_{1}$ and $s_{2}$ such that rational offenders are deterred from committing crimes in both periods. We then minimize the cost of punishment subject to those constraints.

\subsection{Sanctions that Deter Rational Offenders}

To ensure time consistency (subgame perfection), ${ }^{8}$ we work in reverse sequence, starting with the period two decisions of rational offenders. An offender in period two either has a criminal record or not. If not, his expected return from committing a crime is

\footnotetext{
${ }^{5}$ See Cooter (1991), who models crimes and torts as resulting from lapses of this sort.

${ }^{6}$ Thus, for example, an individual is not more likely to be undeterrable in period two if he was undeterrable in period one, and vice versa.

${ }^{7}$ Grogger (1995) shows that the wage penalty declines with time. This factor does not arise in our model since the penalty can only be incurred in the second and final period.
} 
$b-p s_{1}$, while his return from legal employment is $y$. The offender is therefore deterred if $y \geq b-p s_{1},{ }^{9}$ or if

$$
s_{1} \geq \frac{b-y}{p}
$$

Alternatively, if an offender has a criminal record, his expected return from committing a crime in period two is $b-p s_{2}$, while his return from legal employment is $y-\varepsilon$. Thus, he will be deterred if $y-\varepsilon \geq b-p s_{2}$, or if

$$
s_{2} \geq \frac{b+\varepsilon-y}{p} .
$$

Note that the lower bound for $s_{2}$ is larger than for $s_{1}$, reflecting the inferior labor market opportunities of convicted criminals. This is what necessitates a higher sanction for repeat offenders in order to deter them from committing further crimes. Constraints (1) and (2) are shown graphically in Figure 1.

Now consider the behavior of rational offenders in period one. Their two options are to commit a crime, or to work in legal employment. We assume that in comparing these options, they know that they will be deterred from committing future crimes if they are rational in period two (given (1) and (2)), but they also know that they will irrationally commit crimes in period two with probability $\alpha$ regardless of their period one behavior. Foreseeing this, they account for the consequences of this irrationality in making their period one decisions. ${ }^{10}$ Thus, a rational offender calculates his expected lifetime income from committing a crime in period one to be

\footnotetext{
${ }^{8}$ Emons (2004) emphasizes the importance of time consistency in deriving the optimal punishment scheme for repeat offenders, but his model is quite different from ours. Moreover, his results do not explain escalating punishments.

${ }^{9}$ We assume that when indifferent, the offender is deterred.

${ }^{10}$ Our results do not change if offenders cannot foresee, and hence cannot plan for, their possible irrationality.
} 


$$
b-p s_{1}+(1-\alpha)(y-p \varepsilon)+\alpha\left[b-p^{2} s_{2}-p(1-p) s_{1}\right] .
$$

In this expression, $p \varepsilon$ is the expected wage penalty, while the term in square brackets is the expected return from irrational crime in period two (given the offender's period one behavior). Conversely, an offender's expected lifetime income from working legally in period one is

$$
y+(1-\alpha) y+\alpha\left(b-p s_{1}\right)
$$

where the final term again reflects the return from irrational crime in period two.

The rational offender will be deterred from committing a crime in period one if (4) exceeds (3), or, after re-arranging, if

$$
p(1-\alpha p) s_{1}+\alpha p^{2} s_{2}+(1-\alpha) p \varepsilon \geq b-y .
$$

According to this condition, an increase in either $s_{1}$ or $s_{2}$ enhances deterrence in period one, reflecting the notion of "full deterrence" (Shepherd, 2002). Likewise, an increase in the expected period two wage penalty promotes deterrence in period one (Nagin and Waldfogel, 1998), though we saw above that it hampers deterrence of repeat offenders in period two. Finally, if we substitute the lower bounds for $s_{1}$ and $s_{2}$ into (5), it reduces to $p \varepsilon \geq 0$, which clearly holds. It follows that constraints (1) and (2) are sufficient to deter crime by rational offenders in period one as well as two.

\subsection{Cost Minimizing Sanctions}

It remains to derive the socially optimal values of $s_{1}$ and $s_{2}$. As noted above, these are found by minimizing the total cost of punishment subject to the condition that all rational offenders are deterred (i.e., subject to constraints (1) and (2)). 
Total punishment costs equal the number of irrational crimes committed in each period multiplied by the appropriate punishment. ${ }^{11}$ If we normalize the total population of offenders to be one, then the number of irrational offenders in period one is $\alpha$, a fraction $p$ of which are caught and punished. Thus, total expected costs in period one are simply $\alpha p s_{1}{ }^{12}$ In period two, the total number of crimes is the same, but punishment costs differ because some offenders are first-timers (those who did not commit crimes in period one, as well as those who did but were not caught), and some are repeat offenders. The expected cost of punishing first-timers is thus $p\left[\alpha(1-\alpha)+\alpha^{2}(1-p)\right] s_{1}$, while the expected cost of punishing repeat offenders is $p^{2} \alpha^{2} s_{2}$. Summing all costs across the two periods and simplifying yields ${ }^{13}$

$$
T C=p \alpha(2-p \alpha) s_{1}+p^{2} \alpha^{2} s_{2} .
$$

Totally differentiating (6) yields the slope of iso-cost lines in $\left(s_{2}, s_{1}\right)$ space:

$$
\frac{d s_{2}}{d s_{1}}=-\frac{(2-p \alpha)}{p \alpha}<0 .
$$

A set of iso-cost lines is shown in Figure 1. Since costs are decreasing toward the lower left in the diagram, the optimal point occurs at the intersection of the two constraints (i.e., where both are just binding), implying that

$$
\begin{aligned}
& s_{1}^{*}=\frac{b-y}{p} \\
& S_{2}^{*}=\frac{b+\varepsilon-y}{p} .
\end{aligned}
$$

\footnotetext{
${ }^{11}$ Since $p$ is fixed, the cost of apprehension is a fixed cost in each period. Thus, we can ignore it in deriving the optimum.

${ }^{12}$ We assume that society and the offender weigh the cost of punishment equally. If they attach different costs to punishment, as is likely to be true for prison, then we would need to add an additional weighting factor (Polinsky and Shavell, 2000). However, since this would have no effect on our conclusions, we ignore it here.
} 
It follows that punishments are more severe for repeat offenders, reflecting the period two wage penalty suffered by those with a criminal record.

\section{Conclusion}

The observed pattern of penalties in most penal codes implies a rising sanction for repeat offenders. While this accords with common sense, economic models of crime have had unusual difficulty in explaining it (though not from lack of effort). Most existing studies either find no rationale for rising penalties, or provide only qualified explanations. This paper has derived an unambiguous explanation based on the existence of the wage penalty suffered by convicted criminals. Although the threat of a wage penalty may help to deter some first time offenders from embarking on a life of crime (thus possibly allowing lower penalties for first-timers), it actually hinders deterrence of those with a criminal record by making legal employment appear relatively less desirable. To counter this, sanctions for repeat offenders need to be raised. Based on this logic, we showed that the optimal (time consistent) penalty schedule unambiguously entails higher penalties for repeat offenders.

\footnotetext{
${ }^{13}$ We ignore discounting.
} 


\section{References}

Burnovsky, M. and Z. Safra (1994) "Deterrence Effects of Sequential Punishment Policies: Should Repeat Offenders be More Severely Punished?" International Review of Law and Economics 14: 341-350.

Champion, D. (ed.) (1989) The U.S. Sentencing Guidelines: Implications for Criminal Justice. New York: Praeger.

Chu, C., S. Hu, and T. Huang (2000) "Punishing Repeat Offenders More Severely," International Review of Law and Economics 20: 127-140.

Cooter, R. (1991) "Lapses, Conflict, and Akrasia in Torts and Crimes: Towards an Economic Theory of the Will," International Review of Law and Economics 11: 149-164.

Dana, D. (2001) "Rethinking the Puzzle of Escalating Penalties for Repeat Offenders," Yale Law Journal 110: 733-783.

Emons, W. (2004) “Subgame Perfect Punishment for Repeat Offenders," Economic Inquiry 42: 496-502.

Emons, W. (2003) "A Note on the Optimal Punishment for Repeat Offenders," International Review of Law and Economics 23: 253-259.

Grogger, J. (1995) "The Effect of Arrests on the Employment and Earnings of Young Men," Quarterly Journal of Economics 110: 51-71.

Lott, J. (1992a) "An Attempt at Measuring the Total Monetary Penalty from Drug Convictions: The Importance of an Individual's Reputation," Journal of Legal Studies 21: $159-187$.

Lott, J. (1992b) "Do We Punish High Income Criminal too Heavily?" Economic Inquiry 30: $583-608$.

Nagin, D. and J. Waldfogel (1998) "The Effect of Conviction on Income Through the Life Cycle," International Review of Law and Economics 18: 25-40.

Nagin, D. and J. Waldfogel (1995) "The Effects of Criminality and Conviction on the Labor Market Status of Young British Offenders," International Review of Law and Economics 15: 109-126.

Polinsky, A. M. and D. Rubinfeld (1991) "A Model of Fines for Repeat Offenders," Journal of Public Economics 46: 291-306.

Polinsky, A. M. and S. Shavell (2000) "The Economic Theory of Public Law Enforcement," Journal of Economic Literature 38: 45-76. 
Polinsky, A. M. and S. Shavell (1998) "On Offense History and the Theory of Deterrence," International Review of Law and Economics 18: 305-324.

Posner, R. (2003). Economic Analysis of Law, $6^{\text {th }}$ Edition. New York: Aspen Publishers.

Shepherd, J. (2002) "Fear of the First Strike: The Full Deterrence Effect of California's Two- and Three-Strikes Legislation," Journal of Legal Studies 31: 159-201. 


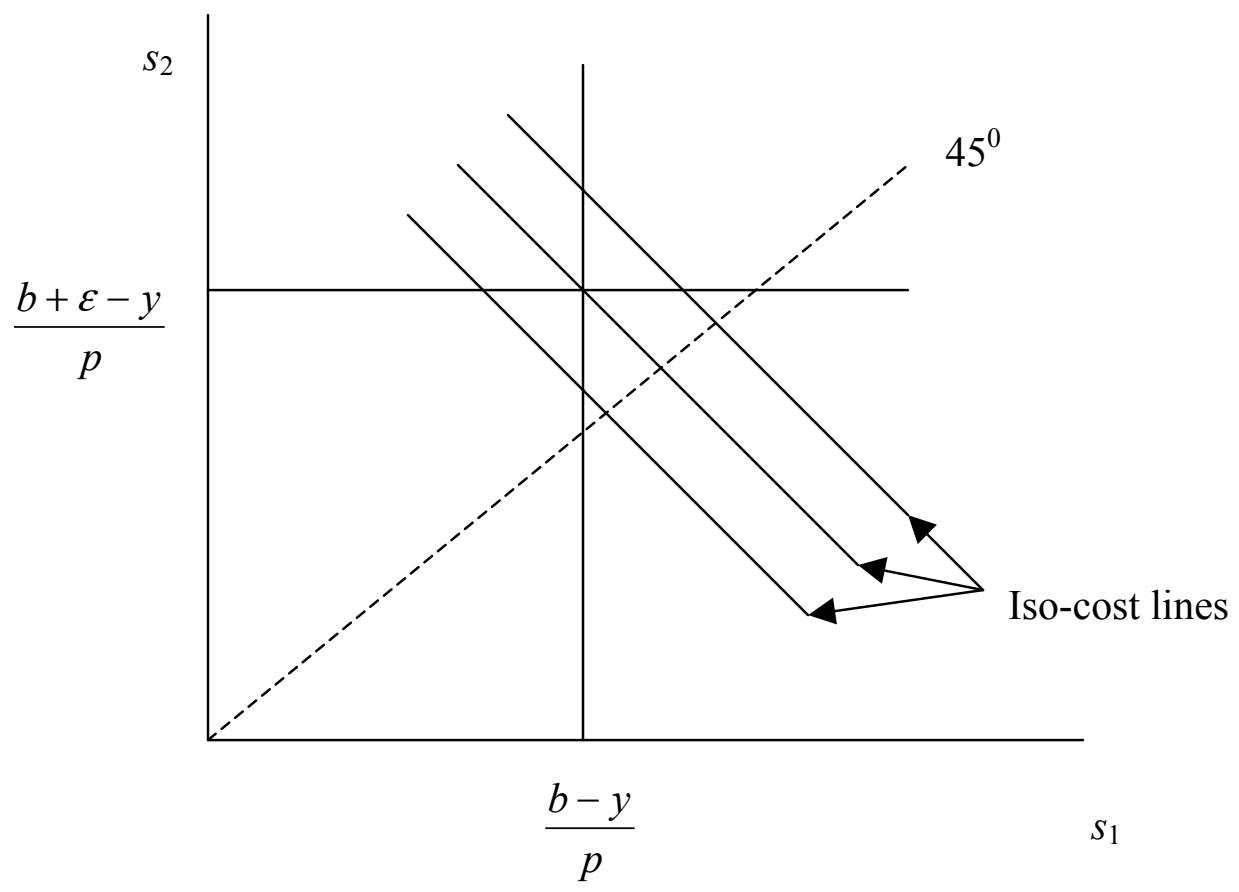

Figure 1: Cost minimizing penalties across periods. 